\title{
Benchmark calculations of K-edge ionization energies for first-row elements using scalar-relativistic core-valence-separated equation-of-motion coupled-cluster methods
}

\author{
Liu, Junzi; Matthews, Devin; Coriani, Sonia; Cheng, Lan
}

Published in:

Journal of Chemical Theory and Computation

Link to article, DOI:

$10.1021 /$ acs.jctc. $8 \mathrm{~b} 01160$

Publication date:

2019

Document Version

Peer reviewed version

Link back to DTU Orbit

Citation (APA):

Liu, J., Matthews, D., Coriani, S., \& Cheng, L. (2019). Benchmark calculations of K-edge ionization energies for first-row elements using scalar-relativistic core-valence-separated equation-of-motion coupled-cluster methods. Journal of Chemical Theory and Computation, 15(3), 1642-1651. https://doi.org/10.1021/acs.jctc.8b01160

\section{General rights}

Copyright and moral rights for the publications made accessible in the public portal are retained by the authors and/or other copyright owners and it is a condition of accessing publications that users recognise and abide by the legal requirements associated with these rights.

- Users may download and print one copy of any publication from the public portal for the purpose of private study or research.

- You may not further distribute the material or use it for any profit-making activity or commercial gain

- You may freely distribute the URL identifying the publication in the public portal 


\section{Quantum Electronic Structure}

Subscriber access provided by DTU Library

\section{Benchmark calculations of K-edge ionization energies for first-row elements using scalar-relativistic core-valence- separated equation-of-motion coupled-cluster methods Junzi Liu, Devin Matthews, Sonia Coriani, and Lan Cheng}

J. Chem. Theory Comput., Just Accepted Manuscript • DOI: 10.1021/acs.jctc.8b01160 • Publication Date (Web): 31 Jan 2019

Downloaded from http://pubs.acs.org on February 8, 2019

\section{Just Accepted}

"Just Accepted" manuscripts have been peer-reviewed and accepted for publication. They are posted online prior to technical editing, formatting for publication and author proofing. The American Chemical Society provides "Just Accepted" as a service to the research community to expedite the dissemination of scientific material as soon as possible after acceptance. "Just Accepted" manuscripts appear in full in PDF format accompanied by an HTML abstract. "Just Accepted" manuscripts have been fully peer reviewed, but should not be considered the official version of record. They are citable by the Digital Object Identifier (DOI®). "Just Accepted" is an optional service offered to authors. Therefore, the "Just Accepted" Web site may not include all articles that will be published in the journal. After a manuscript is technically edited and formatted, it will be removed from the "Just Accepted" Web site and published as an ASAP article. Note that technical editing may introduce minor changes to the manuscript text and/or graphics which could affect content, and all legal disclaimers and ethical guidelines that apply to the journal pertain. ACS cannot be held responsible for errors or consequences arising from the use of information contained in these "Just Accepted" manuscripts. 


\title{
Benchmark calculations of K-edge ionization energies for first-row elements using
} scalar-relativistic core-valence-separated equation-of-motion coupled-cluster methods

\author{
Junzi Liu, ${ }^{\dagger}$ Devin Matthews, ${ }^{\ddagger}$ Sonia Coriani, $₫$ and Lan Cheng $^{*, \dagger}$ \\ $\dagger$ Department of Chemistry, The Johns Hopkins University, Baltimore, Maryland 21218, \\ $U S A$ \\ $\ddagger$ Department of Chemistry, Southern Methodist University, Dallas, Texas 75275, USA \\ IDepartment of Chemistry, Technical University of Denmark, DK-2800 Kongens Lyngby, \\ Denmark \\ E-mail: Icheng24@jhu.edu
}

\begin{abstract}
Benchmark scalar-relativistic core-valence-separated (CVS) equation-of-motion coupledcluster ionization potential (EOMIP-CC) calculations of $21 \mathrm{~K}$-edge ionization energies of $\mathrm{C}, \mathrm{O}, \mathrm{N}$, and $\mathrm{F}$ in 14 molecules are reported. The CVS-EOMIP-CC methods are shown to be numerically more stable and more accurate than the parent EOMIP-CC methods, even when the calculations using the latter can be tightly converged. The superior performance of the CVS scheme is attributed to the exclusion of spurious couplings between core-ionized states and valence continuum states. Systematic improvement of computed K-edge ionization energies within the CVS-EOMIP-CC hierarchy, including the CC singles and doubles (CCSD) method, the CC singles, doubles and


triples (CCSDT) method, and the CC singles, doubles, triples, and quadruples (CCSDTQ) method, is demonstrated, with CCSDTQ yielding essentially quantitative results. Maximum absolute deviations between computed and experimental results amount to $2.54 \mathrm{eV}$ for CCSD/cc-pCVQZ, $0.54 \mathrm{eV}$ for CCSDT/cc-pCVQZ, and $0.23 \mathrm{eV}$ for CCSDT/cc-pCVQZ augmented with quadruples contributions using the cc-pVTZ basis sets. The corresponding standard deviations are $1.91 \mathrm{eV}$ for CCSD/cc-pCVQZ, $0.18 \mathrm{eV}$ for CCSDT/cc-pCVQZ, and $0.10 \mathrm{eV}$ for CCSDT/cc-pCVQZ augmented with quadruples contributions using the cc-pVTZ basis sets. Finally, CVS-EOMIP-CCSDT/ccpCVTZ calculations of core ionization energies in $\mathrm{CH}_{3} \mathrm{CN}$ and $\mathrm{CH}_{3} \mathrm{NC}$ are reported, and experimental re-investigation of carbon 1s ionization energies in $\mathrm{CH}_{3} \mathrm{CN}$ is suggested.

\section{Introduction}

X-ray spectroscopy is widely used for probing electronic structure and dynamics in molecules, solid state, and biological systems. ${ }^{1-4}$ In particular, recent advancements in short-pulse X-ray light sources including synchrotrons, free-electron lasers, and those based on high-harmonic generation ${ }^{5-11}$ have enabled the study of ultrafast nuclear and electronic dynamics. ${ }^{12-17}$ Extensive studies of computational techniques aiming at accurate calculations of X-ray photoelectron and absorption spectra are available in the literature. ${ }^{18,19}$ The computational techniques can be classified into two broad categories. The ones in the first category perform separate orbital optimizations for core-ionized or excited states. The delta-Hartree-Fock $(\Delta \mathrm{HF})$ method, ${ }^{20-23}$ the delta-density-functional-theory $(\triangle \mathrm{DFT}) \operatorname{method}^{23,24}$ as well as its approximate variants, ${ }^{24-27}$ the delta-restricted-active-space self-consistent-field ( $\triangle \mathrm{RASSCF}$ ) method, ${ }^{21,28-30}$ the orthogonality-constrained DFT method, ${ }^{31}$ the static exchange (STEX) method, ${ }^{32,33}$ and the non-orthogonal configuration interaction singles (NOCIS) method ${ }^{34}$ fall into this category. These techniques explicitly account for the strong orbital relaxation induced by the creation of core hole(s) and are usually capable of providing good energies 
for core-ionized/excited states. Calculations with explicit inclusion of dynamical correlation on top of $\Delta \mathrm{HF}$ have also been reported. ${ }^{35-38}$ The techniques in the second category use the ground state of the neutral molecule as the reference state and access core-ionized and excited states via response theory or using a wave operator that accounts for the difference between ground and excited states. The configuration interaction singles (CIS) method, ${ }^{39-41}$ CIS with perturbative inclusion of double excitations (CIS(D)), ${ }^{42}$ time-dependent DFT linear response (TDDFT-LR) theory, ${ }^{18,43}$ the Bethe-Salpeter equation approach, ${ }^{44}$ Green's function methods, ${ }^{45-48}$ equation-of-motion coupled-cluster (EOM-CC) methods ${ }^{49,50}$ /coupled-cluster linear response (CC-LR) theory ${ }^{51,52}$ and multireference coupled-cluster methods ${ }^{53-56}$ belong to this category. We mention that real-time $\mathrm{DFT}^{57-59}$ and $\mathrm{CC}$ methods ${ }^{60}$ for calculations of core-ionized/excited states fall into the second category within the present discussion, as the ionization or excitation energies computed with these methods are identical to those obtained using the corresponding linear response theories.

Response theories (and the methods in the second category in general) are flexible tools for calculations of both energies and properties of excited states. However, additional challenges have to be dealt with in calculations of core-ionized or excited states. Since coreionized and excited states are energetically embedded in continuum states, the convergence of excited-state equations has emerged as a major challenge. Several schemes including the complex polarization propagator (CPP) method, ${ }^{61}$ the (asymmetric) Lanczos algorithm, ${ }^{62}$ the Arnoldi algorithm, ${ }^{49}$ the energy-specific strategy, ${ }^{50}$ and the core-valence separation (CVS) scheme ${ }^{52,63}$ have been proposed in order to resolve the convergence difficulty. Among these approaches, the CVS scheme originally proposed by Cederbaum et al. ${ }^{64}$ appears to be the most promising. The CVS scheme retains only excitations involving at least one core orbitals and thus excludes the problematic pure valence excitations that are (quasi-) degenerate to the core-ionized or excited states of interest. In the literature the CVS scheme has been referred to as "the CVS approximation" to the parent "full" method. However, the "full method" may include spurious couplings between core-ionized or excited states and valence continuum 
states. One motivation of the present study is to examine the numerical significance of this problem of the "full" method. It has indeed been found and will be reported in Section 3.1 that the CVS scheme is superior to the "full" method and thus is the method of choice for treating core-ionized and excited states.

On the other hand, the solution of response equations within the CVS scheme does neglect the contribution from the continuum part of the wave function of core-ionized or excited states. This is a potential source of errors for the computed energies and properties of core-ionized or excited states. Another motivation of this work is to investigate the intrinsic accuracy of this approximation. For this purpose, the hierarchy of CVS-EOMIP-CC methods, ${ }^{65-69}$ including the CC singles and doubles (CCSD) method, ${ }^{66}$ the CC singles, doubles and triples (CCSDT) method ${ }^{70,71}$ as well as CC singles, doubles, triples, and quadruples (CCSDTQ) method, ${ }^{72}$ together with correlation-consistent basis sets ${ }^{73-75}$ have been used to systematically approach the exact solution for the bound part of the wave function. The benchmark set comprises 21 K-edge ionization energies of C, N, O, F in 14 molecules. Note that relativistic effects essentially contribute a constant shift of K-edge ionization energies in $\mathrm{C}, \mathrm{N}, \mathrm{O}$, or F. However, relativistic corrections amount to about $0.1 \mathrm{eV}$ for $\mathrm{C}$ and around 0.7 $\mathrm{eV}$ for F. They are not negligible when high accuracy is desired. ${ }^{76,77}$ In the present study we have used spin-free exact-two-component theory in its one-electron variant (SFX2C-1e) ${ }^{78,79}$ to treat relativistic effects. Theory and computational details are given in Section 2, while the computational results are presented and discussed in Section 3. The conclusion is given in Section 4.

\section{Theory and computational details}

We first briefly recapitulate the equation-of-motion ionization-potential coupled-cluster (EOMIPCC) methods ${ }^{80}$ used in the present study. Throughout the discussion, we follow the standard convention that $\{i, j, \cdots\},\{a, b, \cdots\}$, and $\{p, q, \cdots\}$ denote occupied, virtual, and arbitrary 
orbitals, respectively. The EOMIP-CC wave function $\left|\Psi^{\text {EOMIP-CC }}\right\rangle$ is obtained by applying an "ionization operator" $\hat{R}$ to the ground state CC wave function $\left|\Psi^{\mathrm{CC}}\right\rangle$, i.e.,

$$
\left|\Psi^{\text {EOMIP-CC }}\right\rangle=\hat{R}\left|\Psi^{\mathrm{CC}}\right\rangle
$$

The wave operator of the ground state CC method takes an exponential parametrization and the CC wave function can be written as $\left|\Psi^{\mathrm{CC}}\right\rangle=e^{\hat{T}}|0\rangle$, in which $|0\rangle$ is the reference determinant. The cluster operator $\hat{T}$ is a weighted combination of excitation operators, e.g., in the CC singles and doubles (CCSD) method $\hat{T}=\sum_{i a} t_{i}^{a} a_{a}^{\dagger} a_{i}+\frac{1}{4} \sum_{i j a b} t_{i j}^{a b} a_{a}^{\dagger} a_{b}^{\dagger} a_{j} a_{i}$. The cluster amplitudes are determined by projected amplitude equations

$$
\left\langle\Phi^{\mathrm{EX}}|\bar{H}| 0\right\rangle=0
$$

in which $\bar{H}$ denotes the similarity-transformed Hamiltonian, $\bar{H}=e^{-\hat{T}} \hat{H} e^{\hat{T}}$, and $\Phi^{\mathrm{EX}}$ represents excited determinants generated by the elementary excitation operators in $\hat{T}$, e.g., in CCSD method $\left\{\left|\Phi^{\mathrm{EX}}\right\rangle\right\}=\left\{a_{a}^{\dagger} a_{i}|0\rangle\right\} \cup\left\{a_{a}^{\dagger} a_{b}^{\dagger} a_{i} a_{j}|0\rangle\right\}$. The manifold of elementary ionization operators in $\hat{R}$ is chosen to be consistent with the excitation manifold in $\hat{T}$. In the CCSD method, the ionization operator $\hat{R}$ is a weighted combination of $\left\{a_{i}\right\}$ and $\left\{a_{a}^{\dagger} a_{j} a_{i}\right\}$, i.e., $\hat{R}=\sum_{i} r_{i} a_{i}+\frac{1}{2} \sum_{i j, a} r_{i j}^{a} a_{a}^{\dagger} a_{j} a_{i}$. The amplitudes $r_{i}$ and $r_{i j}^{a}$ are determined by configurationinteraction (CI)-like secular equations involving $\bar{H}$

$$
\left\langle\Phi^{\mathrm{IP}}|[\bar{H}, \hat{R}]| 0\right\rangle=E^{\mathrm{IP}}\left\langle\Phi^{\mathrm{IP}}|\hat{R}| 0\right\rangle
$$

in which $\left|\Phi^{\mathrm{IP}}\right\rangle$ 's are ionized states generated by the same manifold of elementary ionization operators as in $\hat{R}$, e.g., $\left\{\left|\Phi^{\mathrm{IP}, \mathrm{CCSD}}\right\rangle\right\}=\left\{a_{i}|0\rangle\right\} \cup\left\{a_{a}^{\dagger} a_{j} a_{i}|0\rangle\right\}$. In the EOMIP-CC calculations, the ground state equations [Eq. (2)] are first solved and then the secular equation [Eq. (3)] is solved for each ionization energy of interest. The present study has employed the series of CCSD, CCSDT, and CCSDTQ methods to systematically approach the full CI limit. The 
EOMIP-CCSDT method includes triple excitations $\left\{a_{a}^{\dagger} a_{b}^{\dagger} a_{c}^{\dagger} a_{k} a_{j} a_{i}\right\}$ in $\hat{T}$ and ionizations with two shake-up excitations $\left\{a_{a}^{\dagger} a_{b}^{\dagger} a_{k} a_{j} a_{i}\right\}$ in $\hat{R}$, while the EOMIP-CCSDTQ method further includes quadruple excitations $\left\{a_{a}^{\dagger} a_{b}^{\dagger} a_{c}^{\dagger} a_{d}^{\dagger} a_{l} a_{k} a_{j} a_{i}\right\}$ in $\hat{T}$ and ionizations with three shakeup excitations $\left\{a_{a}^{\dagger} a_{b}^{\dagger} a_{c}^{\dagger} a_{l} a_{k} a_{j} a_{i}\right\}$ in $\hat{R}$. As all the molecules studied here are closed-shell systems, the recent implementation of non-orthogonal spin adaptation for CCSDTQ and EOM-CCSDTQ methods ${ }^{81,82}$ has played an essential role in the present calculations. We mention that all EOMIP-CCSDTQ calculations presented here have been carried out using the EOM-CCSDTQ code for excitation energies (EE) together with the "continuum-orbital trick", i.e., the electron to be ionized is promoted into a "continuum" orbital with zero orbital energy and no coupling with other orbitals in order to obtain the ionized state. ${ }^{83}$

The core-valence separation (CVS) scheme includes in $\hat{R}$ only elementary ionization operators that contain at least one core orbital. A simple scheme for the implementation of CVS in a standard EOMIP-CC code suggested by Coriani and Koch has been used in the CVS-EOMIP-CCSD and CVS-EOMIP-CCSDT calculations presented here. Namely, all the $\mathrm{R}$ amplitudes for pure valence ionizations $\left\{r_{i_{v}}\right\},\left\{r_{i_{v} j_{v}}^{a}\right\}$ and etc, in which $\left\{i_{v}, j_{v}, \cdots\right\}$ represents occupied valence orbitals, are set to zero during the solution of EOMIP-CC secular equations. The CVS-EOMEE-CCSDTQ calculations using continuum-orbital trick presented here have been carried out using an efficient implementation of the CVS scheme, in which only the $\mathrm{R}$ amplitudes involving core orbitals are included in the calculation. The details about the efficient implementation of the CVS scheme for the EOM-CCSDT and EOMCCSDTQ methods go beyond the present context and will be published elsewhere. It should be mentioned that the original proposal of CVS by Cederbaum et al. neglects Hamiltonian integrals that couple valence and core orbitals. This leads to the same scheme for the solution of excited-state secular equation adopted here together with the frozen-core approximation for the ground state calculation. ${ }^{84}$ The purpose of the current study is to benchmark the performance of CVS-EOMIP-CC methods for calculations of core ionization energies. In particular, we aim to understand how the results converge with respect to the excitation rank 
and how the near-CVS-FCI limit compares with experiment. Therefore, we have correlated core electrons in the solution of ground state $\mathrm{CC}$ equations for all calculations presented here.

All calculations presented here have been performed using the CFOUR program package. ${ }^{66,80-83,85-87}$ Relativistic effects have been included using spin-free exact two-component theory in its one-electron variant (SFX2C-1e) $)^{78,79}$ with correlation-consistent basis sets ${ }^{73-75}$ recontracted for the SFX2C-1e scheme. The detailed information about the SFX2C-1e recontracted basis sets can be found at www.cfour.de. The experimental equilibrium bond lengths ${ }^{88}$ have been used in calculations for diatomic molecules, while the structures optimized at SFX2C-1e-CCSD(T)/cc-pCVQZ level have been used for all polyatomic molecules. The geometrical parameters are documented in the supplementary material. In order to compare the performance of CVS-EOMIP-CCSD and full EOMIP-CCSD, we carried out CVS-EOMIP-CCSD and full EOMIP-CCSD calculations for 1s ionization energies in HF, $\mathrm{F}_{2}, \mathrm{~N}_{2}, \mathrm{CO}$, and $\mathrm{H}_{2} \mathrm{O}$ using the aug-cc-pCVXZ $(\mathrm{X}=\mathrm{T}, \mathrm{Q}, 5)$ basis sets. To compare the performance of basis sets with and without diffuse functions, CVS-EOMIP-CCSDT calculations have been performed for 1s ionization energies in $\mathrm{HF}, \mathrm{CO}, \mathrm{N}_{2}, \mathrm{~F}_{2}$, and $\mathrm{H}_{2} \mathrm{O}$ using aug-cc-pCVXZ $(\mathrm{X}=\mathrm{D}, \mathrm{T}, \mathrm{Q}, 5)$ and cc-pCVXZ $(\mathrm{X}=\mathrm{D}, \mathrm{T}, \mathrm{Q}, 5)$ sets. The performance of CCSD and CCSDT methods is studied by performing CVS-EOMIP-CCSD and CCSDT calculations of 1s ionization energies in $\mathrm{HF}, \mathrm{CO}, \mathrm{N}_{2}, \mathrm{~F}_{2}$, and $\mathrm{H}_{2} \mathrm{O}$ using cc-pCVXZ $(\mathrm{X}=\mathrm{T}, \mathrm{Q}, 5)$ sets and in $\mathrm{C}_{2} \mathrm{H}_{4}, \mathrm{C}_{2} \mathrm{H}_{2}, \mathrm{CH}_{4}, \mathrm{CH}_{2} \mathrm{O}, \mathrm{CO}_{2}, \mathrm{NNO}, \mathrm{NH}_{3}, \mathrm{HCN}$ and $\mathrm{CH}_{3} \mathrm{OH}$ using cc-pCVTZ and cc-pCVQZ basis sets. Corrections from quadruple excitations have been obtained as the difference between CVS-EOMIP-CCSDTQ and CVS-EOMIP-CCSDT results using the cc-pCVTZ basis sets for HF, $\mathrm{F}_{2}, \mathrm{~N}_{2}, \mathrm{CO}, \mathrm{H}_{2} \mathrm{O}$ and using the cc-pVTZ basis sets for the other polyatomic molecules. We mention that the experimental ionization energies ${ }^{89}$ used in the comparison are all taken from experimental studies without vibrational resolution and thus they approximately correspond to vertical ionization energies. Therefore, it is justified to compare the computed vertical ionization energies with these experimental results. 
Finally, CVS-EOMIP-CCSD calculations using cc-pCVTZ and cc-pCVQZ basis sets and CVS-EOMIP-CCSDT/cc-pCVTZ calculations have been carried out for the $\mathrm{CH}_{3} \mathrm{CN}$ and $\mathrm{CH}_{3} \mathrm{NC}$ molecules. All EOMIP-CC and CVS-EOMIP-CC calculations have been tightly converged; the convergence threshold for the maximum norm of the elements in the EOMIP energy-weighted residue vector is $10^{-5}$ a.u., and the variance of ionization energies is below $10^{-6} \mathrm{E}_{h}$ upon convergence.

\section{Results and Discussion}

\subsection{CVS-EOMIP-CC versus full EOMIP-CC}

As shown in Table 1 and also in Fig. 1, the 1 s ionization energies for $\mathrm{HF}, \mathrm{F}_{2}, \mathrm{~N}_{2}$, CO, and $\mathrm{H}_{2} \mathrm{O}$ computed at the CVS-EOMIP-CCSD level converge smoothly along aug-cc-pCVXZ $(\mathrm{X}=\mathrm{T}, \mathrm{Q}, 5)$ sets. In contrast, the basis-set convergence of the full EOMIP-CCSD results shows significant oscillations for all cases. This irregular performance of the full EOMIPCCSD method can be attributed to spurious couplings between the ionized state and highlying pure valence ionized states that are accidentally (quasi-)degenerate. Note that the latter consists of ionization of a valence electron accompanied by an excitation from a valence orbital to a high-lying virtual orbital and should not significantly contribute to core-ionized state. For example, the wave function from the full EOMIP-CCSD/aug-cc-pCVQZ calculation for the fluorine $1 \mathrm{~s}^{-1}$ state of $\mathrm{F}_{2}$ has a $20 \%$ contamination from pure valence ionizations with similar energies. In other words, when basis sets accidentally cover high-lying (continuum) valence ionized states that are (quasi-)degenerate to core-ionized states of interest, unphysical contributions arise and lead to numerical errors in the ionization energies, even if the full EOMIP-CCSD equations are tightly converged. Therefore, the CVS scheme not only expedites the convergence of the EOMIP-CC equations, but also excludes spurious interactions between core-ionized and valence continuum states. Hence, the CVS-EOMIP-CC methods are better than the corresponding full CVS-EOMIP-CC methods for calculations of 
core-ionized states. Therefore, we have adopted the CVS scheme in all following calculations.

\subsection{Effects of diffuse functions on computed ionization energies}

Diffuse functions do not contribute much to K-edge ionization energies, as core ionization is a spatially localized process. It is demonstrated in Table 2 that CVS-EOMIP-CCSDT results using aug-cc-pCVXZ $(\mathrm{X}=\mathrm{D}, \mathrm{T}, \mathrm{Q}, 5)$ and cc-pCVXZ $(\mathrm{X}=\mathrm{D}, \mathrm{T}, \mathrm{Q}, 5)$ sets converge to essentially the same values; the differences between aug-cc-pCV5Z and cc-pCV5Z results are at most $0.03 \mathrm{eV}$. Interestingly, the cc-pCVXZ results seem to converge more rapidly than the aug-cc-pCVXZ ones. All cc-pCVTZ results are within $0.12 \mathrm{eV}$ in comparison with ccpCV5Z or aug-cc-pCV5Z results, while the aug-cc-pCVTZ results deviate more substantially from the $5 Z$ results. Double-zeta basis sets (aug-cc-pCVDZ and cc-pCVDZ) do not provide accurate results for K-edge ionization energies and show errors greater than $1 \mathrm{eV}$ for all cases. The use of triple-zeta basis lowers basis-set errors by an order of magnitude. Based on the above observations and analyses of basis-set effects, the cc-pCVXZ $(X=T, Q, 5)$ basis sets have been used in the following studies on the convergence of CVS-EOMIP-CC methods with respect to the excitation rank.

\subsection{Accuracy of CVS-EOMIP-CCSD and CVS-EOMIP-CCSDT}

As shown in Tables 3, 5, and 6, the deviation of CVS-EOMIP-CCSD K-edge ionization energies from experimental values is typically $1-3 \mathrm{eV}$, while the corresponding deviations for chemical shifts are usually less than $0.5 \mathrm{eV}$. Here the chemical shifts for the 1s ionization energies of $\mathrm{C}, \mathrm{N}, \mathrm{O}$, and $\mathrm{F}$ are given as the differences with respect to those in $\mathrm{CO}, \mathrm{N}_{2}, \mathrm{CO}$, and $\mathrm{HF}$, respectively. $\mathrm{N}_{2} \mathrm{O}$ appears to be a difficult case, in which the chemical shifts of the terminal nitrogen and the middle nitrogen with respect to $\mathrm{N}_{2}$ still amount to 0.74 and 0.99 $\mathrm{eV}$, respectively (see Table 6). The relatively slow convergence of the computed ionization energies with respect to the excitation rank within CVS-EOMIP-CC for $\mathrm{N}_{2} \mathrm{O}$ indicates the strong orbital relaxation induced by the creation of the core hole in this molecule. The linear 
parametrization of the $\hat{R}$ operator in EOMCC does not efficiently take orbital rotation into account. Consequently, higher excitations are required when aiming at quantitative results. It can be seen from Tables 3, 5, and 6 that agreement between theory and experiment is much improved when triple excitations are included. Most CVS-EOMIP-CCSDT results are within $0.3 \mathrm{eV}$ in comparison with experimental values. The middle nitrogen in $\mathrm{N}_{2} \mathrm{O}$ remains the most difficult case, with the deviation between CVS-EOMIP-CCSDT and experiment still higher than $0.5 \mathrm{eV}$.

We mention that, interestingly, the basis-set convergence of the CCSDT results could be quite different from CCSD. For example, the CVS-EOMIP-CCSD/cc-pCVTZ result for $\mathrm{F}$ 1s ionization energies in $\mathrm{HF}$ is $0.22 \mathrm{eV}$ smaller than the CVS-EOMIP-CCSD/cc-pCV5Z result, while the CVS-EOMIP-CCSDT/cc-pCVTZ value is $0.02 \mathrm{eV}$ higher than the CVSEOMIP-CCSDT/cc-pCV5Z result. Therefore, additivity schemes that augment lower-level $\mathrm{CC}$ results obtained using larger basis sets with corrections from high-level CC calculations using smaller basis sets should be used with care for core ionization energies, especially when aiming at high accuracy. Despite the profound coupling between electron-correlation and basis-set effects, basis-set convergence for core-ionization energies is pretty fast. The ccpCVTZ basis in general provides accurate treatment of basis-set effects, while CVS-EOMIPCCSDT/cc-pCVQZ results are within $0.02 \mathrm{eV}$ in comparison with those of CVS-EOMIPCCSDT/cc-pCV5Z.

\subsection{Quadruples corrections}

For all diatomic molecules in the benchmark set as well as for $\mathrm{H}_{2} \mathrm{O}$, effects of quadruple excitations have been studied at the CVS-EOMIP-CCSDTQ/cc-pCVTZ level and are summarized in Table 3. The absolute values for the quadruples corrections to K-edge ionization energies in these small molecules range from 0.08 to $0.23 \mathrm{eV}$, about an order of magnitude smaller than the corresponding triples corrections. As it is a reasonable assumption that corrections from even higher excitations are smaller, the CVS-EOMIP-CCSDTQ results for 


\subsection{Carbon 1s ionization energies in $\mathrm{CH}_{3} \mathrm{CN}$ and $\mathrm{CH}_{3} \mathrm{NC}$}

CVS-EOMIP-CCSD/cc-pCVTZ, CVS-EOMIP-CCSD/cc-pCVQZ, and CVS-EOMIP-CCSDT/ccpCVTZ calculations have been carried out for $\mathrm{CH}_{3} \mathrm{CN}$ and $\mathrm{CH}_{3} \mathrm{NC}$ and compared with two different sets of experimental results available in the literature. ${ }^{90,91}$ As shown in Table 7, comparison between CVS-EOMIP-CCSD/cc-pCVTZ and CVS-EOMIP-CCSD/cc-pCVQZ confirms that basis-set effects beyond cc-pCVTZ play a minor role. On the other hand, 
triples corrections are significant. Although the absolute magnitude for the triples correction to the relative shift between the two carbons in $\mathrm{CH}_{3} \mathrm{CN}$ is only $0.17 \mathrm{eV}$, the inclusion of triples corrections reverses the ordering of carbon 1s ionization energies for the methyl carbon and the cyano carbon. The computational results $(292.90 \mathrm{eV}$ for cyano carbon and $292.81 \mathrm{eV}$ for methyl carbon with a relative shift of $0.09 \mathrm{eV}$ ) differ significantly from the more recent experimental results $(292.45 \mathrm{eV}$ for cyano carbon and $292.98 \mathrm{eV}$ for methyl carbon with a relative shift of $-0.53 \mathrm{eV})$. Since the triples correction to this relative shift is only $0.17 \mathrm{eV}$, we do not expect the corresponding quadruples correction to be close to the difference of $-0.62 \mathrm{eV}$ between the computational and experimental results. Interestingly, the computational results qualitatively agree with an earlier experiment with a lower resolution (293.2 for cyano carbon and 293.1 for methyl carbon with a relative shift of $0.1 \mathrm{eV}$ ). It is also observed that, for $\mathrm{CH}_{3} \mathrm{NC}$, our CVS-EOMIP-CCSDT/cc-pCVTZ results agree very well with the more recent experimental study, and differ considerably from the earlier ones. We would suggest an experimental re-investigation of $\mathrm{CH}_{3} \mathrm{CN}$ to settle these issues.

\section{Conclusion}

The present manuscript reports benchmark calculations for K-edge ionization energies in C, N, O, F using core-valence-separated (CVS) equation-of-motion ionization-potential coupledcluster (EOMIP-CC) methods. It is shown that the CVS scheme excludes spurious couplings between core-ionized states and valence continuum states and thus the CVS-EOMIP-CC methods turn out to be better than the parent EOMIP-CC methods in terms of numerical accuracy. Convergence of computed K-edge ionization energies within the hierarchy of CVSEOMIP-CC methods has been carefully studied. Essentially quantitative agreement between computed and experimental results is obtained when quadruples contributions are included. We mention that the magnitude of the remaining errors of CCSDTQ for the electronic contributions to K-edge ionization energies are comparable with or even smaller than that of 
1

2

3

4

5

6

7

8

9

10

11

12

13

14

15

16

17

18

19

20

21

22

23

24

25

26

27

28

29

30

31

32

33

34

35

36

37

38

39

40

41

42

43

44

45

46

47

48

49

50

51

52

53

54

55

56

57

58

59

60

vibrational corrections. Therefore, computational studies with vibrational corrections taken into account and the comparison of the corresponding results with vibrationally resolved experimental results would be of great interest for future studies. Finally, computational results for carbon 1s ionization energies in $\mathrm{CH}_{3} \mathrm{CN}$ and $\mathrm{CH}_{3} \mathrm{NC}$ suggest an experimental re-investigation of these molecules. 

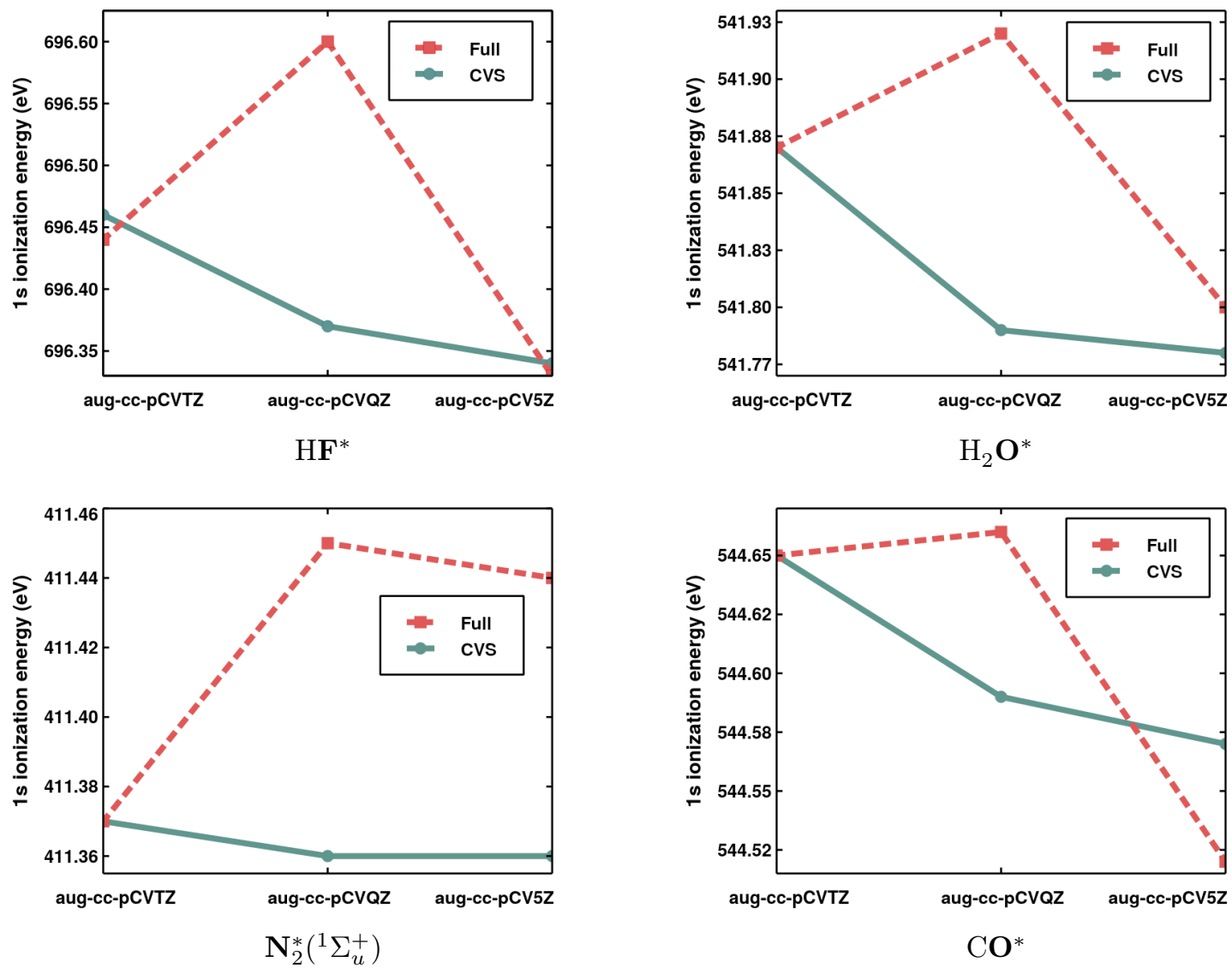

Figure 1: 1s ionization energies (in eV) computed at the EOMIP-CCSD level for the atoms in bold letter marked with an asterisk. "CVS" denotes the use of the core-valence separation scheme. "Full" stands for the solution of EOMIP-CCSD equations in the full singles and doubles space. 
Table 1: 1s ionization energies (in $\mathrm{eV}$ ) computed at the EOMIP-CCSD level for the atoms in bold letter marked with an asterisk. "CVS" denotes the use of the core-valence separation scheme, while "full" stands for the solution of EOMIP-CCSD equations in the full singles and doubles space.

\begin{tabular}{|c|c|c|c|c|}
\hline & & aug-cc-pCVTZ & aug-cc-pCVQZ & aug-cc-pCV5Z \\
\hline \multirow[t]{2}{*}{$\mathrm{HF}^{*}$} & full & 696.44 & 696.60 & 696.33 \\
\hline & CVS & 696.46 & 696.37 & 696.34 \\
\hline \multirow[t]{2}{*}{$\mathbf{F}_{2}^{*}\left({ }^{1} \Sigma_{g}^{+}\right)$} & full & 699.20 & 699.59 & 699.07 \\
\hline & CVS & 699.23 & 699.14 & 699.12 \\
\hline \multirow[t]{2}{*}{$\mathbf{F}_{2}^{*}\left({ }^{1} \Sigma_{u}^{+}\right)$} & full & 699.19 & 699.03 & 699.06 \\
\hline & CVS & 699.22 & 699.13 & 699.11 \\
\hline \multirow[t]{2}{*}{$\mathbf{N}_{2}^{*}\left({ }^{1} \Sigma_{g}^{+}\right)$} & full & 411.47 & 411.51 & 411.48 \\
\hline & CVS & 411.47 & 411.46 & 411.46 \\
\hline \multirow[t]{2}{*}{$\mathbf{N}_{2}^{*}\left({ }^{1} \Sigma_{u}^{+}\right)$} & full & 411.37 & 411.45 & 411.44 \\
\hline & CVS & 411.37 & 411.36 & 411.36 \\
\hline \multirow[t]{2}{*}{$\mathrm{C}^{*} \mathrm{O}$} & full & 297.73 & 297.73 & 297.74 \\
\hline & CVS & 297.72 & 297.71 & 297.72 \\
\hline \multirow[t]{2}{*}{$\mathrm{CO}^{*}$} & full & 544.65 & 544.66 & 544.52 \\
\hline & CVS & 544.65 & 544.59 & 544.57 \\
\hline \multirow[t]{2}{*}{$\mathrm{H}_{2} \mathrm{O}^{*}$} & full & 541.87 & 541.92 & 541.80 \\
\hline & CVS & 541.87 & 541.79 & 541.78 \\
\hline
\end{tabular}


Table 2: 1s ionization energies (in eV) computed at the CVS-EOMIP-CCSDT level for the atoms in bold letter marked with an asterisk. "CXZ" and "ACXZ" (X=D, $\mathrm{T}, \mathrm{Q}, 5)$ represent cc-pCVXZ and aug-cc-pCVXZ sets, respectively. The SFX2C-1e scheme has been used to treat scalar-relativistic effects.

\begin{tabular}{lllllllll}
\hline Molecule & ACDZ & ACTZ & ACQZ & AC5Z & CDZ & CTZ & CQZ & C5Z \\
\hline HF$^{*}$ & 696.66 & 694.45 & 694.28 & 694.23 & 695.98 & 694.22 & 694.19 & 694.20 \\
$\mathbf{C}^{*} \mathrm{O}$ & 297.85 & 296.53 & 296.46 & 296.45 & 297.83 & 296.47 & 296.44 & 296.45 \\
$\mathrm{CO}^{*}$ & 544.50 & 542.64 & 542.50 & 542.46 & 544.29 & 542.57 & 542.48 & 542.46 \\
$\mathbf{N}_{2}^{*}\left({ }^{1} \Sigma_{g}^{+}\right)$ & 411.89 & 410.20 & 410.11 & 410.09 & 411.69 & 410.11 & 410.08 & 410.07 \\
$\mathbf{N}_{2}^{*}\left({ }^{1} \Sigma_{u}^{+}\right)$ & 411.80 & 410.11 & 410.03 & 410.01 & 411.60 & 410.03 & 409.99 & 409.99 \\
$\mathbf{F}_{2}^{*}\left({ }^{1} \Sigma_{g}^{+}\right)$ & 699.10 & 696.90 & 696.74 & 696.70 & 698.59 & 696.73 & 696.67 & 696.67 \\
$\mathbf{F}_{2}^{*}\left({ }^{1} \Sigma_{u}^{+}\right)$ & 699.09 & 696.89 & 696.73 & 696.69 & 698.58 & 696.72 & 696.66 & 696.66 \\
$\mathrm{H}_{2} \mathbf{O}^{*}$ & 541.90 & 540.00 & 539.85 & 539.81 & 541.36 & 539.79 & 539.76 & 539.78 \\
\hline
\end{tabular}


Table 3: 1s ionization energies (in eV) for the atoms in bold letter marked with an asterisk. "CXZ" (X=T, Q, 5) denotes cc-pCVXZ sets. The deviations from experimental values are enclosed in parentheses. The core-valence separation scheme has been used. Scalar-relativistic effects have been taken into account using the SFX2C-1e scheme.

\begin{tabular}{|c|c|c|c|c|c|c|c|c|c|}
\hline \multirow{2}{*}{ Molecule } & \multicolumn{3}{|c|}{ EOMIP-CCSD } & \multicolumn{3}{|c|}{ EOMIP-CCSDT } & \multirow{2}{*}{$\frac{\text { EOMIP-CCSDTQ }}{\mathrm{CTZ}}$} & \multirow{2}{*}{ total $^{\mathrm{a}}$} & \multirow{2}{*}{ Exp. ${ }^{89}$} \\
\hline & $\mathrm{CTZ}$ & CQZ & $\mathrm{C} 5 \mathrm{Z}$ & $\mathrm{CTZ}$ & CQZ & $\mathrm{C} 5 \mathrm{Z}$ & & & \\
\hline \multirow[t]{2}{*}{$\mathrm{HF}^{*}$} & 696.09 & 696.23 & 696.31 & 694.22 & 694.19 & 694.20 & 694.45 & 694.44 & 694.23 \\
\hline & $(1.86)$ & $(2.00)$ & $(2.08)$ & $(-0.01)$ & $(-0.04)$ & $(-0.03)$ & $(0.22)$ & $(0.21)$ & \\
\hline \multirow[t]{2}{*}{$\mathrm{C}^{*} \mathrm{O}$} & 297.64 & 297.69 & 297.71 & 296.47 & 296.44 & 296.45 & 296.30 & 296.27 & 296.21 \\
\hline & $(1.43)$ & $(1.48)$ & $(1.50)$ & $(0.26)$ & $(0.23)$ & $(0.24)$ & $(0.09)$ & $(0.06)$ & \\
\hline \multirow[t]{2}{*}{$\mathrm{CO}^{*}$} & 544.57 & 544.56 & 544.57 & 542.57 & 542.48 & 542.46 & 542.68 & 542.57 & 542.55 \\
\hline & $(2.02)$ & $(2.01)$ & $(2.02)$ & $(0.02)$ & $(-0.07)$ & $(-0.09)$ & $(0.13)$ & $(0.02)$ & \\
\hline \multirow[t]{2}{*}{$\mathbf{N}_{2}^{*}\left({ }^{1} \Sigma_{g}^{+}\right)$} & 411.35 & 411.41 & 411.43 & 410.11 & 410.08 & 410.07 & 410.03 & 409.99 & 409.98 \\
\hline & $(1.37)$ & $(1.43)$ & $(1.45)$ & $(0.13)$ & $(0.10)$ & $(0.09)$ & $(0.05)$ & $(0.01)$ & \\
\hline \multirow[t]{2}{*}{$\mathbf{N}_{2}^{*}\left({ }^{1} \Sigma_{u}^{+}\right)$} & 411.25 & 411.31 & 411.33 & 410.03 & 409.99 & 409.99 & 409.95 & 409.91 & 409.98 \\
\hline & $(1.27)$ & $(1.33)$ & $(1.35)$ & $(0.05)$ & $(0.01)$ & $(0.01)$ & $(-0.03)$ & $(-0.07)$ & \\
\hline \multirow[t]{2}{*}{$\mathbf{F}_{2}^{*}\left({ }^{1} \Sigma_{g}^{+}\right)$} & 699.01 & 699.06 & 699.09 & 696.73 & 696.67 & 696.67 & 696.82 & 696.75 & 696.69 \\
\hline & $(2.32)$ & $(2.37)$ & $(2.40)$ & $(0.04)$ & $(-0.02)$ & $(-0.02)$ & $(0.13)$ & $(0.06)$ & \\
\hline \multirow[t]{2}{*}{$\mathbf{F}_{2}^{*}\left({ }^{1} \Sigma_{u}^{+}\right)$} & 699.00 & 699.05 & 699.08 & 696.72 & 696.66 & 696.66 & 696.81 & 696.75 & 696.69 \\
\hline & $(2.31)$ & $(2.36)$ & $(2.39)$ & $(0.03)$ & $(-0.03)$ & $(-0.03)$ & $(0.12)$ & $(0.06)$ & \\
\hline \multirow[t]{2}{*}{$\mathrm{H}_{2} \mathrm{O}^{*}$} & 541.53 & 541.65 & 541.74 & 539.79 & 539.76 & 539.78 & 539.99 & 539.98 & 539.90 \\
\hline & (1.63) & $(1.75)$ & $(1.84)$ & $(-0.11)$ & $(-0.14)$ & $(-0.11)$ & $(0.09)$ & $(0.08)$ & \\
\hline
\end{tabular}

${ }^{\text {a }}$ CCSDT/cc-pCV5Z results augmented with quadruples corrections obtained using the ccpCVTZ basis. 
Table 4: 1s ionization energies (in $\mathrm{eV}$ ) for the atoms in bold letter marked with an asterisk computed using CVS-EOMIP-CC methods.

\begin{tabular}{|c|c|c|c|c|}
\hline Molecules & Method & cc-pCVTZ & cc-pCVTZ/cc-pVTZa & cc-pVTZ \\
\hline \multirow[t]{3}{*}{$\mathbf{C}^{*} \mathrm{O}$} & CCSDT & 296.47 & 296.47 & 295.97 \\
\hline & CCSDTQ & 296.30 & 296.29 & 295.81 \\
\hline & $\Delta_{\mathrm{Q}}$ & -0.17 & -0.17 & -0.16 \\
\hline \multirow[t]{3}{*}{$\mathrm{CO}^{*}$} & CCSDT & 542.57 & 542.57 & 542.21 \\
\hline & CCSDTQ & 542.68 & 542.68 & 542.34 \\
\hline & $\Delta_{\mathrm{Q}}$ & 0.11 & 0.11 & 0.13 \\
\hline \multirow[t]{3}{*}{$\mathbf{N}_{2}^{*}\left(\Sigma_{g}^{+}\right)$} & CCSDT & 410.11 & 410.11 & 409.68 \\
\hline & CCSDTQ & 410.03 & 410.03 & 409.62 \\
\hline & $\Delta_{\mathrm{Q}}$ & -0.08 & -0.08 & -0.07 \\
\hline \multirow[t]{3}{*}{$\mathbf{N}_{2}^{*}\left(\Sigma_{u}^{+}\right)$} & CCSDT & 410.03 & 410.03 & 409.60 \\
\hline & CCSDTQ & 409.95 & 409.95 & 409.53 \\
\hline & $\Delta_{\mathrm{Q}}$ & -0.08 & -0.08 & -0.06 \\
\hline \multirow[t]{3}{*}{$\mathbf{F}_{2}^{*}\left(\Sigma_{g}^{+}\right)$} & CCSDT & 696.73 & 696.73 & 696.45 \\
\hline & CCSDTQ & 696.82 & 696.82 & 696.57 \\
\hline & $\Delta_{\mathrm{Q}}$ & 0.09 & 0.09 & 0.13 \\
\hline \multirow[t]{3}{*}{$\mathbf{F}_{2}^{*}\left(\Sigma_{u}^{+}\right)$} & CCSDT & 696.72 & 696.72 & 696.44 \\
\hline & CCSDTQ & 696.81 & 696.81 & 696.56 \\
\hline & $\Delta_{\mathrm{Q}}$ & 0.09 & 0.09 & 0.13 \\
\hline \multirow[t]{3}{*}{$\mathrm{HF}^{*}$} & CCSDT & 694.22 & 694.22 & 693.93 \\
\hline & CCSDTQ & 694.45 & 694.45 & 694.19 \\
\hline & $\Delta_{\mathrm{Q}}$ & 0.23 & 0.23 & 0.26 \\
\hline
\end{tabular}

a cc-pCVTZ basis for the targeted atom and cc-pVTZ basis for the other atoms. 
Table 5: Computed 1s ionization energies (in $\mathrm{eV}$ ) for the atoms in bold letter marked with an asterisk. CXZ $(\mathrm{X}=\mathrm{T}, \mathrm{Q})$ denote cc-pCVXZ basis sets. The core-valence separation scheme has been used, and relativistic effects have been treated using the SFX2C-1e scheme. "MAE" represents the mean absolute deviation with respect to experimental values.

\begin{tabular}{|c|c|c|c|c|c|c|c|c|}
\hline & \multicolumn{2}{|c|}{ EOMIP-CCSD } & \multicolumn{2}{|c|}{ EOMIP-CCSDT } & \multirow{2}{*}{$\Delta_{\mathrm{Q}}^{\mathrm{a}}$} & \multirow{2}{*}{ Best theory ${ }^{b}$} & \multirow{2}{*}{ Exp. ${ }^{89}$} & \multirow{2}{*}{$\Delta($ Theory-Exp $)$} \\
\hline & $\mathrm{CTZ}$ & CQZ & $\mathrm{CTZ}$ & CQZ & & & & \\
\hline $\mathrm{C}_{2}^{*} \mathrm{H}_{4}\left(A_{g}\right)$ & 292.32 & 292.32 & 290.89 & 290.81 & 0.00 & 290.81 & 290.82 & -0.01 \\
\hline $\mathbf{C}_{2}^{*} \mathrm{H}_{4}\left(B_{2 u}\right)$ & 292.26 & 292.27 & 290.85 & 290.76 & 0.00 & 290.77 & 290.82 & -0.05 \\
\hline $\mathbf{C}_{2}^{*} \mathrm{H}_{2}\left({ }^{1} \Sigma_{g}^{+}\right)$ & 292.72 & 292.73 & 291.45 & 291.36 & -0.06 & 291.31 & 291.14 & 0.17 \\
\hline $\mathbf{C}_{2}^{*} \mathrm{H}_{2}\left({ }^{1} \Sigma_{u}^{+}\right)$ & 292.62 & 292.63 & 291.36 & 291.28 & -0.05 & 291.22 & 291.14 & 0.08 \\
\hline $\mathrm{C}^{*} \mathrm{H}_{4}$ & 292.07 & 292.04 & 290.86 & 290.75 & 0.05 & 290.80 & 290.91 & -0.11 \\
\hline $\mathrm{CH}_{2} \mathrm{O}^{*}$ & 541.68 & 541.70 & 539.44 & 539.36 & 0.12 & 539.48 & 539.48 & 0.00 \\
\hline $\mathrm{C}^{*} \mathrm{H}_{2} \mathrm{O}$ & 295.94 & 295.99 & 294.62 & 294.58 & -0.12 & 294.46 & 294.47 & -0.01 \\
\hline $\mathrm{CO}_{2}^{*}$ & 543.70 & 543.73 & 541.40 & 541.35 & -0.01 & 541.34 & 541.28 & 0.06 \\
\hline $\mathrm{C}^{*} \mathrm{O}_{2}$ & 299.52 & 299.59 & 298.03 & 298.02 & -0.26 & 297.76 & 297.69 & 0.07 \\
\hline $\mathrm{NNO}^{*}$ & 543.92 & 543.96 & 541.63 & 541.57 & -0.02 & 541.55 & 541.42 & 0.13 \\
\hline $\mathrm{NN}^{*} \mathrm{O}$ & 414.90 & 414.96 & 413.15 & 413.13 & -0.31 & 412.82 & 412.59 & 0.23 \\
\hline $\mathbf{N}^{*} \mathrm{NO}$ & 410.76 & 410.83 & 408.92 & 408.90 & -0.11 & 408.79 & 408.71 & 0.08 \\
\hline $\mathbf{N} * \mathrm{H}_{3}$ & 407.04 & 407.13 & 405.55 & 405.51 & 0.14 & 405.65 & 405.56 & 0.09 \\
\hline $\mathrm{HCN}^{*}$ & 408.45 & 408.47 & 406.88 & 406.81 & 0.01 & 406.82 & 406.78 & 0.04 \\
\hline $\mathrm{HC}^{*} \mathrm{~N}$ & 294.66 & 294.68 & 293.59 & 293.53 & -0.12 & 293.41 & 293.40 & 0.01 \\
\hline $\mathrm{CH}_{3} \mathrm{O}^{*} \mathrm{H}$ & 541.05 & 541.11 & 539.00 & 538.95 & - & - & 539.11 & -0.16 \\
\hline $\mathrm{C}^{*} \mathrm{H}_{3} \mathrm{OH}$ & 293.76 & 293.79 & 292.47 & 292.41 & - & - & 292.43 & -0.02 \\
\hline MAE & 1.74 & 1.78 & 0.16 & 0.15 & - & 0.08 & - & - \\
\hline
\end{tabular}

${ }^{a}$ Quadruples corrections obtained using the cc-pVTZ basis.

b CCSDT/cc-pCVQZ results augmented with quadruples corrections obtained using the cc-pVTZ basis. 
Table 6: Chemical shifts (in $\mathrm{eV}$ ) of $\mathrm{C}$ and $\mathrm{O}$ 1s ionization energies (IEs) relative to $\mathrm{CO}, \mathrm{N}$ 1s IEs relative to $\mathrm{N}_{2}$, and $\mathrm{F}$ 1s IEs relative to HF. The cc-pCVQZ basis has been used in all CVS-EOMIP-CCSD and CCSDT calculations, while all quadruples corrections have been obtained using the cc-pVTZ basis. The deviations between computation and experiment are given in parenthesis.

\begin{tabular}{|c|c|c|c|c|}
\hline & Experiment & CCSD & CCSDT & CCSDTQ \\
\hline $\mathbf{C}^{*} \mathrm{O}$ & 296.21 & 297.69 & 296.44 & 296.28 \\
\hline $\mathrm{C}^{*} \mathrm{H}_{4}$ & -5.30 & $-5.64(-0.34)$ & $-5.69(-0.39)$ & $-5.48(-0.18)$ \\
\hline $\mathrm{C}_{2}^{*} \mathrm{H}_{2}$ & -5.07 & $-5.01(0.06)$ & $-5.12(-0.05)^{\mathrm{a}}$ & $-5.01(0.06)^{a}$ \\
\hline $\mathrm{C}_{2}^{*} \mathrm{H}_{4}$ & -5.39 & $-5.39(0.00)$ & $-5.65(-0.26)^{\mathrm{a}}$ & $-5.49(-0.10)^{a}$ \\
\hline $\mathrm{C}^{*} \mathrm{H}_{2} \mathrm{O}$ & -1.74 & $-1.70(0.04)$ & $-1.86(-0.12)$ & $-1.82(-0.08)$ \\
\hline $\mathrm{C}^{*} \mathrm{O}_{2}$ & 1.48 & $1.90(0.42)$ & $1.58(0.10)$ & $1.48(0.00)$ \\
\hline $\mathrm{HC}^{*} \mathrm{~N}$ & -2.81 & $-3.00(-0.19)$ & $-2.91(-0.10)$ & $-2.87(-0.06)$ \\
\hline $\mathbf{C}^{*} \mathrm{H}_{3} \mathrm{OH}$ & -3.78 & $-3.90(-0.12)$ & $-4.03(-0.25)$ & - \\
\hline $\mathbf{N}_{2}^{*}$ & 409.98 & $411.36^{\mathrm{a}}$ & $410.03^{\mathrm{a}}$ & $409.97^{\mathrm{a}}$ \\
\hline $\mathbf{N}^{*} \mathrm{NO}$ & -1.27 & $-0.53(0.74)$ & $-1.13(0.14)$ & $-1.17(0.10)$ \\
\hline $\mathrm{NN}^{*} \mathrm{O}$ & 2.61 & $3.60(0.99)$ & $3.10(0.49)$ & $2.85(0.24)$ \\
\hline $\mathbf{N}^{*} \mathrm{H}_{3}$ & -4.42 & $-4.23(0.19)$ & $-4.52(-0.10)$ & $-4.32(0.10)$ \\
\hline $\mathrm{HCN}^{*}$ & -3.20 & $-2.88(0.32)$ & $-3.22(-0.02)$ & $-3.15(0.05)$ \\
\hline $\mathrm{CO}^{*}$ & 542.55 & 544.56 & 542.48 & 542.61 \\
\hline $\mathrm{H}_{2} \mathrm{O}^{*}$ & -2.65 & $-2.91(-0.26)$ & $-2.71(-0.06)$ & $-2.63(0.02)$ \\
\hline $\mathrm{CH}_{2} \mathrm{O}^{*}$ & -3.07 & $-2.86(0.21)$ & $-3.12(-0.05)$ & $-3.13(-0.06)$ \\
\hline $\mathrm{CO}_{2}^{*}$ & -1.27 & $-0.83(0.44)$ & $-1.13(0.14)$ & $-1.27(0.00)$ \\
\hline $\mathrm{N}_{2} \mathrm{O}^{*}$ & -1.13 & $-0.60(0.53)$ & $-0.90(0.23)$ & $-1.06(0.07)$ \\
\hline $\mathrm{CH}_{3} \mathrm{O}^{*} \mathrm{H}$ & -3.44 & $-3.45(-0.01)$ & $-3.53(-0.09)$ & - \\
\hline $\mathrm{HF}^{*}$ & 694.23 & 696.23 & 694.19 & 694.45 \\
\hline $\mathbf{F}_{2}^{*}$ & 2.46 & $2.82(0.36)^{\mathrm{a}}$ & $2.47(0.01)^{\mathrm{a}}$ & $2.34(-0.12)^{\mathrm{a}}$ \\
\hline
\end{tabular}

a An average of gerade and ungerade states. 
Table 7: 1s ionization energies (in $\mathrm{eV}$ ) for the atoms in bold letter marked with an asterisk.

\begin{tabular}{|c|c|c|c|c|c|}
\hline & \multirow{2}{*}{ Exp. ${ }^{91}$} & \multirow{2}{*}{ Exp. ${ }^{90}$} & \multicolumn{2}{|c|}{ CVS-EOMIP-CCSD } & \multirow{2}{*}{$\frac{\text { CVS-EOMIP-CCSDT }}{\text { cc-pCVTZ }}$} \\
\hline & & & cc-pCVTZ & cc-pCVQZ & \\
\hline $\mathrm{CH}_{3} \mathbf{C}^{*} \mathrm{~N}$ & 292.45 & 293.2 & 294.06 & 294.09 & 292.90 \\
\hline $\mathrm{C}^{*} \mathrm{H}_{3} \mathrm{CN}$ & 292.98 & 293.1 & 294.13 & 294.13 & 292.81 \\
\hline $\mathrm{CH}_{3} \mathrm{CN}^{*}$ & 405.64 & 405.9 & 407.52 & 407.54 & 405.71 \\
\hline $\mathrm{CH}_{3} \mathrm{NC}^{*}$ & 292.37 & 293.8 & 294.07 & 294.12 & 292.35 \\
\hline $\mathrm{C}^{*} \mathrm{H}_{3} \mathrm{NC}$ & 293.35 & 293.1 & 294.78 & 294.78 & 293.41 \\
\hline $\mathrm{CH}_{3} \mathbf{N}^{*} \mathrm{C}$ & 406.67 & 407.1 & 408.38 & 408.40 & 407.02 \\
\hline
\end{tabular}




\section{Acknowledgement}

L. C. is grateful to Johns Hopkins University for the start-up fund. D. M. thanks Southern Methodist University for the start-up fund. S. C. acknowledges support from DTU Chemistry and from the Independent Research Fund Denmark - DFF-Forskningsprojekt2 grant no. 7014-00258B. All the calculations presented here have been carried out using computational facilities of Maryland Advanced Research Computing Center (MARCC). L. C. is indebted to Jaime Combariza at MARCC for assistance in performing the computations. L. C. is grateful to Jürgen Gauss (Mainz) for helpful remarks and for reading the manuscript.

\section{Supporting Information Available}

The geometrical parameters for the molecules used in the present study have been compiled and given in the supplementary material. This material is available free of charge via the Internet at http://pubs.acs.org/.

\section{References}

(1) Stolow, A.; Bragg, A. E.; Neumark, D. M. Femtosecond time-resolved photoelectron spectroscopy. Chem. Rev. 2004, 104, 1719-1757.

(2) Bressler, C.; Chergui, M. Ultrafast x-ray absorption spectroscopy. Chem. Rev. 2004, 104, 1781-1812.

(3) Neutzo, R.; Wouts, R.; Van Der Spoel, D.; Weckert, E.; Hajdu, J. Potential for biomolecular imaging with femtosecond X-ray pulses. Nature 2000, 406, 752-757.

(4) van Bokhoven, J. A., Lamberti, C., Eds. X-ray absorption and X-ray emission spectroscopy: theory and application; Wiley \& Sons, Ltd: Somerset, NJ, USA, 2016. 
(5) Mobilio, S., Boscherini, F., Meneghini, C., Eds. Synchrotron radiation: basics, methods and applications; Springer-Verlag Berlin Heidelberg, 2015.

(6) Schoenlein, R.; Chattopadhyay, S.; Chong, H.; Glover, T.; Heimann, P.; Shank, C.; Zholents, A.; Zolotorev, M. Generation of femtosecond pulses of synchrotron radiation. Science 2000, 287, 2237-2240.

(7) Young, L.; Ueda, K.; Gühr, M.; Bucksbaum, P. H.; Simon, M.; Mukamel, S.; Rohringer, N.; Prince, K. C.; Masciovecchio, C.; Meyer, M.; Rudenko, A.; Rolles, D.; Bostedt, C.; Fuchs, M.; Reis, D. A.; Santra, R.; Kapteyn, H.; Murnane, M.; Ibrahim, H.; Legare, F.; Vrakking, M.; Isinger, M.; Kroon, D.; Gisselbrecht, M.; L'Huillier, A.; Worner, H. J.; Leone, S. R. Roadmap of ultrafast x-ray atomic and molecular physics. J. Phys. B:At. Mol. Opt. Phys. 2018, 51, 032003.

(8) Ackermann, W.; Asova, G.; Ayvazyan, V.; Azima, A.; Baboi, N.; Bähr, J.; Balandin, V.; Beutner, B.; Brandt, A.; Bolzmann, A.; Brinkmann, R.; Brovko, O. I.; Castellano, M.; Castro, P.; Catani, L.; Chiadroni, E.; Choroba, S.; Cianchi, A.; Costello, J. T.; Cubaynes, D.; Dardis, J.; Decking, W.; Delsim-Hashemi, H.; Delserieys, A.; Di Pirro, G.; Dohlus, M.; Düsterer, S.; Eckhardt, A.; Edwards, H. T.; Faatz, B.; Feldhaus, J.; Flöttmann, K.; Frisch, J.; Fröhlich, L.; Garvey, T.; Gensch, U.; Gerth, C.; Görler, M.; Golubeva, N.; Grabosch, H. J.; Grecki, M.; Grimm, O.; Hacker, K.; Hahn, U.; Han, J. H.; Honkavaara, K.; Hott, T.; Hüning, M.; Ivanisenko, Y.; Jaeschke, E.; Jalmuzna, W.; Jezynski, T.; Kammering, R.; Katalev, V.; Kavanagh, K.; Kennedy, E. T.; Khodyachykh, S.; Klose, K.; Kocharyan, V.; Körfer, M.; Kollewe, M.; Koprek, W.; Korepanov, S.; Kostin, D.; Krassilnikov, M.; Kube, G.; Kuhlmann, M.; Lewis, C. L.; Lilje, L.; Limberg, T.; Lipka, D.; Löhl, F.; Luna, H.; Luong, M.; Martins, M.; Meyer, M.; Michelato, P.; Miltchev, V.; Möller, W. D.; Monaco, L.; Müller, W. F.; Napieralski, O.; Napoly, O.; Nicolosi, P.; Nölle, D.; Nuñez, T.; Oppelt, A.; Pagani, C.; Paparella, R.; Pchalek, N.; Pedregosa-Gutierrez, J.; Petersen, B.; Petrosyan, B.; Petrosyan, G.; Pet- 
rosyan, L.; Pflüger, J.; Plönjes, E.; Poletto, L.; Pozniak, K.; Prat, E.; Proch, D.; Pucyk, P.; Radcliffe, P.; Redlin, H.; Rehlich, K.; Richter, M.; Roehrs, M.; Roensch, J.; Romaniuk, R.; Ross, M.; Rossbach, J.; Rybnikov, V.; Sachwitz, M.; Saldin, E. L.; Sandner, W.; Schlarb, H.; Schmidt, B.; Schmitz, M.; Schmüser, P.; Schneider, J. R.; Schneidmiller, E. A.; Schnepp, S.; Schreiber, S.; Seidel, M.; Sertore, D.; Shabunov, A. V.; Simon, C.; Simrock, S.; Sombrowski, E.; Sorokin, A. A.; Spanknebel, P.; Spesyvtsev, R.; Staykov, L.; Steffen, B.; Stephan, F.; Stulle, F.; Thom, H.; Tiedtke, K.; Tischer, M.; Toleikis, S.; Treusch, R.; Trines, D.; Tsakov, I.; Vogel, E.; Weiland, T.; Weise, H.; Wellhöfer, M.; Wendt, M.; Will, I.; Winter, A.; Wittenburg, K.; Wurth, W.; Yeates, P.; Yurkov, M. V.; Zagorodnov, I.; Zapfe, K. Operation of a free-electron laser from the extreme ultraviolet to the water window. Nature Photon. 2007, 1, 336-342.

(9) Emma, P.; Akre, R.; Arthur, J.; Bionta, R.; Bostedt, C.; Bozek, J.; Brachmann, A.; Bucksbaum, P.; Coffee, R.; Decker, F. J.; Ding, Y.; Dowell, D.; Edstrom, S.; Fisher, A.; Frisch, J.; Gilevich, S.; Hastings, J.; Hays, G.; Hering, P.; Huang, Z.; Iverson, R.; Loos, H.; Messerschmidt, M.; Miahnahri, A.; Moeller, S.; Nuhn, H. D.; Pile, G.; Ratner, D.; Rzepiela, J.; Schultz, D.; Smith, T.; Stefan, P.; Tompkins, H.; Turner, J.; Welch, J.; White, W.; Wu, J.; Yocky, G.; Galayda, J. First lasing and operation of an ångstrom-wavelength free-electron laser. Nature Photon. 2010, 4, 641-647.

(10) Allaria, E.; Appio, R.; Badano, L.; Barletta, W. A.; Bassanese, S.; Biedron, S. G.; Borga, A.; Busetto, E.; Castronovo, D.; Cinquegrana, P.; Cleva, S.; Cocco, D.; Cornacchia, M.; Craievich, P.; Cudin, I.; D’Auria, G.; Dal Forno, M.; Danailov, M. B.; De Monte, R.; De Ninno, G.; Delgiusto, P.; Demidovich, A.; Di Mitri, S.; Diviacco, B.; Fabris, A.; Fabris, R.; Fawley, W.; Ferianis, M.; Ferrari, E.; Ferry, S.; Froehlich, L.; Furlan, P.; Gaio, G.; Gelmetti, F.; Giannessi, L.; Giannini, M.; Gobessi, R.; Ivanov, R.; Karantzoulis, E.; Lonza, M.; Lutman, A.; Mahieu, B.; Milloch, M.; Milton, S. V.; Musardo, M.; Nikolov, I.; Noe, S.; Parmigiani, F.; Penco, G.; Petronio, M.; Pivetta, L.; 
Predonzani, M.; Rossi, F.; Rumiz, L.; Salom, A.; Scafuri, C.; Serpico, C.; Sigalotti, P.; Spampinati, S.; Spezzani, C.; Svandrlik, M.; Svetina, C.; Tazzari, S.; Trovo, M.; Umer, R.; Vascotto, A.; Veronese, M.; Visintini, R.; Zaccaria, M.; Zangrando, D.; Zangrando, M. Highly coherent and stable pulses from the FERMI seeded free-electron laser in the extreme ultraviolet. Nature Photon. 2012, 6, 699-704.

(11) Ishikawa, T.; Aoyagi, H.; Asaka, T.; Asano, Y.; Azumi, N.; Bizen, T.; Ego, H.; Fukami, K.; Fukui, T.; Furukawa, Y.; Goto, S.; Hanaki, H.; Hara, T.; Hasegawa, T.; Hatsui, T.; Higashiya, A.; Hirono, T.; Hosoda, N.; Ishii, M.; Inagaki, T.; Inubushi, Y.; Itoga, T.; Joti, Y.; Kago, M.; Kameshima, T.; Kimura, H.; Kirihara, Y.; Kiyomichi, A.; Kobayashi, T.; Kondo, C.; Kudo, T.; Maesaka, H.; Maréchal, X. M.; Masuda, T.; Matsubara, S.; Matsumoto, T.; Matsushita, T.; Matsui, S.; Nagasono, M.; Nariyama, N.; Ohashi, H.; Ohata, T.; Ohshima, T.; Ono, S.; Otake, Y.; Saji, C.; Sakurai, T.; Sato, T.; Sawada, K.; Seike, T.; Shirasawa, K.; Sugimoto, T.; Suzuki, S.; Takahashi, S.; Takebe, H.; Takeshita, K.; Tamasaku, K.; Tanaka, H.; Tanaka, R.; Tanaka, T.; Togashi, T.; Togawa, K.; Tokuhisa, A.; Tomizawa, H.; Tono, K.; Wu, S.; Yabashi, M.; Yamaga, M.; Yamashita, A.; Yanagida, K.; Zhang, C.; Shintake, T.; Kitamura, H.; Kumagai, N. A compact X-ray free-electron laser emitting in the sub-ångström region. Nature Photon. 2012, 6, 540-544.

(12) Bressler, C.; Milne, C.; Pham, V.; ElNahhas, A.; van der Veen, R. M.; Gawelda, W.; Johnson, S.; Beaud, P.; Grolimund, D.; Kaiser, M.; Borca, C. N.; Ingold, G.; Abela, R.; Chergui, M. Femtosecond XANES study of the light-induced spin crossover dynamics in an iron(II) complex. Science 2009, 323, 489-492.

(13) Goulielmakis, E.; Loh, Z. H.; Wirth, A.; Santra, R.; Rohringer, N.; Yakovlev, V. S.; Zherebtsov, S.; Pfeifer, T.; Azzeer, A. M.; Kling, M. F.; Leone, S. R.; Krausz, F. Real-time observation of valence electron motion. Nature 2010, 466, 739-743.

(14) Erk, B.; Boll, R.; Trippel, S.; Anielski, D.; Foucar, L.; Rudek, B.; Epp, S. W.; Cof- 
fee, R.; Carron, S.; Schorb, S.; Ferguson, K. R.; Swiggers, M.; Bozek, J. D.; Simon, M.; Marchenko, T.; Küpper, J.; Schlichting, I.; Ullrich, J.; Bostedt, C.; Rolles, D.; Rudenko, A. Imaging charge transfer in iodomethane upon X-ray photoabsorption. Science 2014, 345, 288-291.

(15) Kuleff, A. I.; Kryzhevoi, N. V.; Pernpointner, M.; Cederbaum, L. S. Core ionization initiates subfemtosecond charge migration in the valence shell of molecules. Phy. Rev. Lett. 2016, 117, 1-5.

(16) Pertot, Y.; Schmidt, C.; Matthews, M.; Chauvet, A.; Huppert, M.; Svoboda, V.; von Conta, A.; Tehlar, A.; Baykusheva, D.; Wolf, J.-P. P.; Wörner, H. J. Time-resolved Xray absorption spectroscopy with a water window high-harmonic source. Science $\mathbf{2 0 1 7}$, $355,264-267$.

(17) Kraus, P. M.; Zürch, M.; Cushing, S. K.; Neumark, D. M.; Leone, S. R. The ultrafast X-ray spectroscopic revolution in chemical dynamics. Nat. Rev. Chem. 2018, 2, 82-94.

(18) Besley, N. A.; Asmuruf, F. A. Time-dependent density functional theory calculations of the spectroscopy of core electrons. Phys. Chem. Chem. Phys. 2010, 12, 12024-12039.

(19) Norman, P.; Dreuw, A. Simulating X-ray spectroscopies and calculating core-excited states of molecules. Chem. Rev. 2018, 118, 7208-7248.

(20) Bagus, P. S. Self-consistent-field wave functions for hole states of some Ne-like and Ar-like ions. Phys. Rev. 1965, 139, A619-A634.

(21) Naves De Brito, A.; Correia, N.; Svensson, S.; Agren, H. A theoretical study of X-ray photoelectron spectra of model molecules for polymethylmethacrylate. J. Chem. Phys. 1991, 95, 2965-2974.

(22) Schmitt, A.; Schirmer, J. Molecular K-shell excitation spectra in the relaxed-core Hartree-Fock approximation. Chem. Phys. 1992, 164, 1-9. 
(23) Besley, N. A.; Gilbert, A. T. B.; Gill, P. M. W. Self-consistent-field calculations of core excited states. J. Chem. Phys. 2009, 130, 124308.

(24) Triguero, L.; Plashkevych, O.; Pettersson, L.; Ågren, H. Separate state vs. transition state Kohn-Sham calculations of X-ray photoelectron binding energies and chemical shifts. J. Electron Spectrosc. Relat. Phenom. 1999, 104, 195-207.

(25) Chong, D. P. Accurate calculation of core-electron binding energies by the densityfunctional method. Chem. Phys. Lett. 1995, 232, 486-490.

(26) Chong, D. P. Density-functional calculation of core-electron binding energies of C, N, O, and F. J. Chem. Phys. 1995, 103, 1842-1845.

(27) Triguero, L.; Pettersson, L.; Ågren, H. Calculations of near-edge X-ray absorption spectra of gas-phase and chemisorbed molecules by means of density-functional and transition-potential theory. Phys. Rev. B: Condens. Matter Mater. Phys. 1998, 58, $8097-8110$.

(28) Jensen, H. J. Aa.; Jørgensen, P.; Ågren, H. Efficient optimization of large scale MCSCF wave functions with a restricted step algorithm. J. Chem. Phys. 1987, 87, 451-466.

(29) Ågren, H.; Jensen, H. J. Aa. Relaxation and correlation contributions to molecular double core ionization energies. Chem. Phys. 1993, 172, 45-57.

(30) Bagus, P. S.; Sousa, C.; Illas, F. Consequences of electron correlation for XPS binding energies: Representative case for $\mathrm{C}(1 \mathrm{~s})$ and $\mathrm{O}(1 \mathrm{~s})$ XPS of CO. J. Chem. Phys. 2016, $145,144303$.

(31) Verma, P.; Derricotte, W. D.; Evangelista, F. A. Predicting near edge X-ray absorption spectra with the spin-free exact-two-component hamiltonian and orthogonality constrained density functional theory. J. Chem. Theory Comput. 2016, 12, 144-156. 
(32) Ågren, H.; Carravetta, V.; Vahtras, O.; Pettersson, L. G. Direct, atomic orbital, static exchange calculations of photoabsorption spectra of large molecules and clusters. Chem. Phys. Lett. 1994, 222, 75-81.

(33) Ekström, U.; Norman, P.; Carravetta, V. Relativistic four-component static-exchange approximation for core-excitation processes in molecules. Phys. Rev. A 2006, 73, 22501.

(34) Oosterbaan, K. J.; White, A. F.; Head-Gordon, M. Non-orthogonal configuration interaction with single substitutions for the calculation of core-excited states. J. Chem. Phys. 2018, 149, 044116.

(35) Nooijen, M.; Bartlett, R. J. Description of core-excitation spectra by the open-shell electron-attachment equation-of-motion coupled cluster method. J. Chem. Phys. 1995, 102, 6735-6756.

(36) Ohtsuka, Y.; Nakatsuji, H. Inner-shell ionizations and satellites studied by the openshell reference symmetry-adapted cluster/symmetry-adapted cluster configurationinteraction method. J. Chem. Phys. 2006, 124, 054110.

(37) Holme, A.; Børve, K. J.; Sæthre, L. J.; Thomas, T. D. Accuracy of calculated chemical shifts in carbon 1s ionization energies from single-reference ab initio methods and density functional theory. J. Chem. Theory Comput. 2011, 7, 4104-4114.

(38) Besley, N. A. Equation of motion coupled cluster theory calculations of the X-ray emission spectroscopy of water. Chem. Phys. Lett. 2012, 542, 42-46.

(39) Maganas, D.; DeBeer, S.; Neese, F. Restricted open-shell configuration interaction cluster calculations of the L-edge X-ray absorption study of $\mathrm{TiO}_{2}$ and $\mathrm{CaF}_{2}$ solids. Inorg. Chem. 2014, 53, 6374-6385.

(40) Toffoli, D.; Decleva, P. A Multichannel Least-Squares B-Spline Approach to Molecular 
Photoionization: Theory, Implementation, and Applications within the ConfigurationInteraction Singles Approximation. J. Chem. Theory Comput. 2016, 12, 4996-5008.

(41) Ehlert, C.; Klamroth, T. The quest for best suited references for configuration interaction singles calculations of core excited states. J. Comput. Chem. 2017, 38, 116-126.

(42) Asmuruf, F. A.; Besley, N. A. Calculation of near-edge X-ray absorption fine structure with the CIS(D) method. Chem. Phys. Lett. 2008, 463, 267-271.

(43) DeBeer George, S.; Petrenko, T.; Neese, F. Prediction of Iron K-Edge Absorption Spectra Using Time-Dependent Density Functional Theory. J. Phys. Chem. A 2008, 112, 12936-12943.

(44) Vinson, J.; Rehr, J. J.; Kas, J. J.; Shirley, E. L. Bethe-Salpeter equation calculations of core excitation spectra. Phys. Rev. B 2011, 83, 115106.

(45) Barth, A.; Cederbaum, L. S. Many-body theory of core-calence excitations. Phys. Rev. A 1981, 23, 1038-1061.

(46) Barth, A.; Schirmer, J. Theoretical core-level excitation spectra of $\mathrm{N}_{2}$ and CO by a new polarisation propagator method. J. Phys. B: At. Mol. Phys. 1985, 18, 867-885.

(47) Trofimov, A. B.; Moskovskaya, T.; Gromov, E. V.; Vitkovskaya, N. M.; Schirmer, J. Core-level electronic spectra in $\mathrm{ADC}(2)$ approximation for polarization propagator: Carbon monoxide and nitrogen molecules. J. Struct. Chem. 2000, 41, 483-494.

(48) Wenzel, J.; Holzer, A.; Wormit, M.; Dreuw, A. Analysis and comparison of CVS-ADC approaches up to third order for the calculation of core-excited states. J. Chem. Phys. 2015, 142, 214104.

(49) Southworth, S. H.; Wehlitz, R.; Picón, A.; Lehmann, C. S.; Cheng, L.; Stanton, J. F. Inner-shell photoionization and core-hole decay of $\mathrm{Xe}_{\text {and }} \mathrm{XeF}_{2}$. J. Chem. Phys. 2015, 142, 224302. 
(50) Peng, B.; Lestrange, P. J.; Goings, J. J.; Caricato, M.; Li, X. Energy-specific equationof-motion coupled-cluster methods for high-energy excited states : Application to Kedge X-ray absorption spectroscopy. J. Chem. Theory Comput. 2015, 11, 4146-4153.

(51) Coriani, S.; Christiansen, O.; Fransson, T.; Norman, P. Coupled-cluster response theory for near-edge X-ray-absorption fine structure of atoms and molecules. Phys. Rev. A: At., Mol., Opt. Phys. 2012, 85, 022507.

(52) Coriani, S.; Koch, H. Communication : X-ray absorption spectra and core-ionization potentials within a core-valence separated coupled cluster framework. J. Chem. Phys. 2015, 143, 181103.

(53) Datta, D.; Mukherjee, D. An explicitly spin-free compact open-shell coupled cluster theory using a multireference combinatoric exponential ansatz: Formal development and pilot applications. J. Chem. Phys. 2009, 131.

(54) Brabec, J.; Bhaskaran-Nair, K.; Govind, N.; Pittner, J.; Kowalski, K. Communication: Application of state-specific multireference coupled cluster methods to core-level excitations. J. Chem. Phys. 2012, 137, 171101.

(55) Sen, S.; Shee, A.; Mukherjee, D. A study of the ionisation and excitation energies of core electrons using a unitary group adapted state universal approach. Mol. Phys. 2013, $111,2625-2639$.

(56) Dutta, A. K.; Gupta, J.; Vaval, N.; Pal, S. Intermediate Hamiltonian Fock space multireference coupled cluster approach to core excitation spectra. J. Chem. Theory Comput. 2014, 10, 3656-3668.

(57) Akama, T.; Nakai, H. Short-time Fourier transform analysis of real-time time-dependent Hartree-Fock and time-dependent density functional theory calculations with Gaussian basis functions. J. Chem. Phys. 2010, 132, 054104. 
(58) Akama, T.; Imamura, Y.; Nakai, H. Application of Real-time Time-dependent Density Functional Theory with the CVB3LYP Functional to Core Excitations. Chem. Lett. 2010, 39, 407-409.

(59) Lopata, K.; Van Kuiken, B. E.; Khalil, M.; Govind, N. Linear-response and real-time time-dependent density functional theory studies of core-level near-edge X-ray absorption. J. Chem. Theory Comput. 2012, 8, 3284-3292.

(60) Nascimento, D. R.; DePrince, A. E. Simulation of near-edge X-ray absorption fine structure with time-dependent equation-of-motion coupled-cluster theory. J. Chem. Phys. Lett. 2017, 8, 2951-2957.

(61) Kauczor, J.; Norman, P. Efficient calculations of molecular linear response properties for spectral regions. J. Chem. Theory Comput. 2014, 10, 2449-2455.

(62) Coriani, S.; Fransson, T.; Christiansen, O.; Norman, P. Asymmetric-Lanczos-ChainDriven Implementation of Electronic Resonance Convergent Coupled-Cluster Linear Response Theory. J. Chem. Theory Comput. 2012, 8, 1616-1628.

(63) Schirmer, J.; Thiel, A. An intermediate state representation approach to K-shell ionization in molecules. I. Theory. J. Chem. Phys. 2001, 115, 10621-10635.

(64) Cederbaum, L. S.; Domcke, W.; Schirmer, J. Many-body theory of core holes. Phys. Rev. A: At., Mol., Opt. Phys. 1980, 22, 206-222.

(65) Koch, H.; Jørgensen, P. Coupled cluster response functions. J. Chem. Phys. 1990, 93, $3333-3344$.

(66) Stanton, J. F.; Bartlett, R. J. The equation of motion coupled-cluster method. A systematic biorthogonal approach to molecular excitation energies, transition probabilities, and excited state properties. J. Chem. Phys. 1993, 98, 7029. 
(67) Krylov, A. I. Equation-of-Motion Coupled-Cluster Methods for Open-Shell and Electronically Excited Species: The Hitchhiker's Guide to Fock Space. Annu. Rev. Phys. Chem. 2008, 59, 433-462.

(68) Bartlett, R. J. Coupled-cluster theory and its equation-of-motion extensions. WIREs Comput Mol Sci 2012, 2, 126-138.

(69) Sneskov, K.; Christiansen, O. Excited state coupled cluster methods. WIREs Comput Mol Sci 2012, 2, 566-584.

(70) Kucharski, S. A.; Włoch, M.; Musiał, M.; Bartlett, R. J. Coupled-cluster theory for excited electronic states: The full equation-of-motion coupled-cluster single, double, and triple excitation method. J. Chem. Phys. 2001, 115, 8263-8266.

(71) Kowalski, K.; Piecuch, P. The active-space equation-of-motion coupled-cluster methods for excited electronic states: Full EOMCCSDt. J. Chem. Phys. 2001, 115, 643-651.

(72) Kállay, M.; Gauss, J. Calculation of excited-state properties using general coupledcluster and configuration-interaction models. J. Chem. Phys. 2004, 121, 9257-9269.

(73) Dunning, T. H. Gaussian basis sets for use in correlated molecular calculations. I. The atoms boron through neon and hydrogen. J. Chem. Phys. 1989, 90, 1007-1023.

(74) Woon, D. E.; Dunning, T. H. Gaussian basis sets for use in correlated molecular calculations. V. Core-valence basis sets for boron through neon. J. Chem. Phys. 1995, 103, $4572-4585$.

(75) Kendall, R. A.; Dunning, T. H.; Harrison, R. J. Electron affinities of the first-row atoms revisited. Systematic basis sets and wave functions. J. Chem. Phys. 1992, 96, 6796-6806. 
(76) Tashiro, M.; Ehara, M.; Fukuzawa, H.; Ueda, K.; Buth, C.; Kryzhevoi, N. V.; Cederbaum, L. S. Molecular double core hole electron spectroscopy for chemical analysis. J. Chem. Phys. 2010, 132, 184302.

(77) Myhre, R. H.; Wolf, T. J.; Cheng, L.; Nandi, S.; Coriani, S.; Gühr, M.; Koch, H. A theoretical and experimental benchmark study of core-excited states in nitrogen. J. Chem. Phys. 2018, 148, 064106.

(78) Dyall, K. G. Interfacing relativistic and nonrelativistic methods. IV. One- and twoelectron scalar approximations. J. Chem. Phys. 2001, 115, 9136-9143.

(79) Liu, W.; Peng, D. Exact two-component Hamiltonians revisited. J. Chem. Phys. 2009, 131,31104 .

(80) Stanton, J. F.; Gauss, J. Analytic energy derivatives for ionized states described by the equation-of-motion coupled cluster method. J. Chem. Phys. 1994, 101, 8938-8944.

(81) Matthews, D. A.; Stanton, J. F. Non-orthogonal spin-adaptation of coupled cluster methods: A new implementation of methods including quadruple excitations. J. Chem. Phys. 2015, 142, 064108.

(82) Baraban, J. H.; Matthews, D. A.; Stanton, J. F. Communication: An accurate calculation of the $\mathrm{S}_{1} \mathrm{C}_{2} \mathrm{H}_{2}$ cis-trans isomerization barrier height. J. Chem. Phys. 2016, 144, 111102.

(83) Stanton, J. F.; Gauss, J. A simple scheme for the direct calculation of ionization potentials with coupled-cluster theory that exploits established excitation energy methods. J. Chem. Phys. 1999, 111, 8785-8788.

(84) López Vidal, M.; Feng, X.; Epifanovsky, E.; Krylov, A.; Coriani, S. A New and Efficient Equation-of-Motion Coupled-Cluster Framework for Core-Excited and Core-Ionized States. 2018, doi:10.26434/chemrxiv.7211942.v1. 
(85) CFOUR, Coupled-Cluster techniques for Computational Chemistry, a quantumchemical program package by J.F. Stanton, J. Gauss, L. Cheng, M.E. Harding, D.A. Matthews, P.G. Szalay with contributions from A.A. Auer, R.J. Bartlett, U. Benedikt, C. Berger, D.E. Bernholdt, Y.J. Bomble, O. Christiansen, F. Engel, R. Faber, M. Heckert, M. Hilgenberg, O. Heun, C. Huber, T.-C. Jagau, D. Jonsson, J. Jusélius, T. Kirsch, K. Klein, W.J. Lauderdale, F. Lipparini, T. Metzroth, L.A. Mück, D.P. O’Neill, D.R. Price, E. Prochnow, C. Puzzarini, K. Ruud, F. Schiffmann, W. Schwalbach, C. Simmons, S. Stopkowicz, A. Tajti, J. Vázquez, F. Wang, J.D. Watts and the integral packages MOLECULE (J. Almlöf and P.R. Taylor), PROPS (P.R. Taylor), ABACUS (T. Helgaker, H.J. Aa. Jensen, P. Jørgensen, and J. Olsen), and ECP routines by A. V. Mitin and C. van Wüllen. For the current version, see http://www.cfour.de.

(86) Bomble, Y. J.; Sattelmeyer, K. W.; Stanton, J. F.; Gauss, J. On the vertical excitation energy of cyclopentadiene. J. Chem. Phys. 2004, 121, 5236-5240.

(87) Cheng, L.; Gauss, J. Analytic energy gradients for the spin-free exact two-component theory using an exact block diagonalization for the one-electron Dirac Hamiltonian. J. Chem. Phys. 2011, 135, 084114.

(88) Huber, K. P.; Herzberg, G. Molecular Spectra and Molecular Structure: Constants od Diatomic Molecules; Van Nostrand Reinhold: New York, 1979.

(89) Jolly, W. L.; Bomden, K. D.; Eyermann, C. J. Core-electron binding energies for gaseous atoms and molecules. Atom Data Nucl Data 1984, 31, 433-493.

(90) Barber, M.; Baybutt, P.; Conner, J. A.; Hillier, I. H.; Meredith, W.; Saunders, V. R. In Electron Spectroscopy; Shirley, E., Ed.; North-Holland Publishing: Amsterdam, 1972.

(91) Beach, D. B.; Eyermann, C. J.; Smit, S. P.; Xiang, S. F.; Jolly, W. L. Applications of the Equivalent Cores Approximation. The Determination of Proton Affinities and 
Isocyanide-to-Nitrile Isomerization Energies from Core Binding Energies. J. Am. Chem.

Soc. 1984, 106, 536-539. 


\section{Graphical TOC Entry}

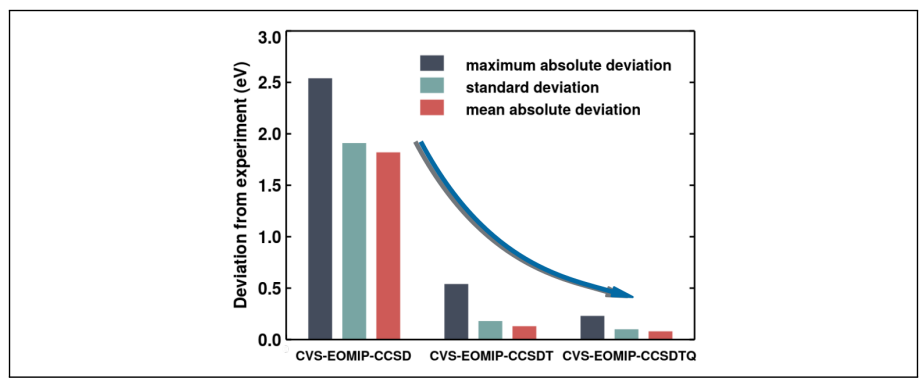

